\title{
Self-efficacy dan Optimisme sebagai Prediktor Subjective Well-Being pada Mahasiswa Tahun Pertama
}

\author{
Riangga Novrianto, Anggia Kargenti Evanurul Marettih \\ riangganovrianto@gmail.com
}

\author{
Fakultas Psikologi, UIN Sultan Syarif Kasim Riau, Pekanbaru, Indonesia
}

\begin{abstract}
This study examined self-efficacy and optimism in predicting subjective well being of firstyear undergraduate students. Participants were first-year undergraduate students of UIN Sultan Syarif Kasim Riau (N=372; 121 males, 251 females). Participants completed the Positive and Negative Affect Schedule (PANAS), Satisfaction With Life Scale, General SelfEfficacy Scale and Life Orientation Test-Revised (LOT-R). Multiple regression analysis was conducted to examine how the predictors contribute to subjective well-being. Results indicated that self-efficacy and optimism predicted first-year undergraduate students' subjective well-being $(F(2,369)=53.920 ; p<0.01)$. Results also indicated that self-efficacy have a higher contribution $(\beta=0.403 ; p<0.01)$ than optimism $(\beta=0.137 ; p<0.01)$. In conclusion, self-efficacy and optimism are important in predicting subjective well-being firstyear undergraduate students.
\end{abstract}

Keywords: optimism; self-efficacy; subjective well-being

Penelitian ini bertujuan untuk mengetahui prediksi self-efficacy dan optimisme terhadap subjective well-being pada mahasiswa tahun pertama. Sebanyak 372 orang mahasiswa tahun pertama UIN Sultan Syarif Kasim Riau ( $N=372$; 121 laki-laki, 251 perempuan) menjadi partisipan di dalam penelitian ini. Partisipan penelitian mengisi adaptasi Skala Positive and Negative Affect Schedule (PANAS), Satisfaction With Life Scale, General Self-Efficacy Scale, dan Life Orientation Test- Revised (LOT-R). Analisis regresi berganda dilakukan untuk mengetahui bagaimana kedua prediktor berkontribusi terhadap subjective well-being. Hasil penelitian menunjukkan self-efficacy dan optimisme secara bersama dapat memprediksi subjective well-being pada mahasiswa tahun pertama $(F(2,369)=53.920$; $p<0.01)$. Hasil penelitian juga menunjukkan bahwa self-efficacy memiliki kontribusi yang lebih besar $(\beta=0.403 ; \mathrm{p}<0.01)$ bila dibandingkan dengan optimisme $(\beta=0.137 ; \mathrm{p}<0.01)$. Sehingga, dapat disimpulkan bahwa self-efficacy dan optimisme memiliki peran penting dalam memprediksi subjective well-being pada mahasiswa tahun pertama.

Kata kunci: optimisme; efikasi diri; kesejahteraan subjektif

Received: August 14, 2018 Accepted: November 20, 2018

How to cite: Novrianto, R., \& Marettih, A. K. E. (2018). Self-efficacy dan Optimisme sebagai Prediktor Subjective Well-Being pada Mahasiswa Tahun Pertama. MEDIAPSI, 4(2), 83-91. doi:

https://doi.org/10.21776/ub.mps.2018.004.02.4

\section{Pendahuluan}

Tahun pertama perkuliahan merupakan salah satu periode terpenting bagi mahasiswa. Periode ini merupakan fase transisi yang berpengaruh terhadap kehidupan perkuliahan mahasiswa tahun pertama. Tantangan awal yang akan dihadapi oleh mahasiswa tahun pertama adalah peralihan dari suasana sekolah menengah ke suasana perkuliahan (Montgomery \& Côté, 2003). Mahasiswa tahun pertama akan menghadapi berbagai perubahan yang berbeda dengan tingkat pendidikan sebelumnya.

Perubahan yang harus dihadapi mahasiswa tahun pertama adalah antara lain perubahan metode belajar, perubahan sistem administrasi pendidikan, perubahan lingkaran pertemanan, hingga perubahan lingkungan tempat tinggal bagi mahasiswa yang berasal 
dari luar kota. Perubahan-perubahan tersebut menuntut tanggung jawab pribadi, kreativitas, serta kemandirian dari mahasiswa. Dalam menghadapi berbagai perubahan di periode transisi ini mahasiswa tahun pertama akan memunculkan keadaan emosi negatif yang merupakan faktor rendahnya subjective wellbeing (Hou \& Liu, 2016; Denovan \& Macaskill, 2017).

Gall, Evans, dan Bellerose (2000) menjelaskan bahwa perubahan-perubahan yang dihadapi oleh mahasiswa dalam kehidupan perkuliahan dapat menjadi stressor yang memengaruhi keadaan subjective wellbeing. Sejalan dengan hal tersebut, penelitian yang dilakukan oleh Kulaksizoğlu dan Topuz (2014) menunjukkan bahwa mahasiswa tahun pertama cenderung memiliki tingkat subjective well-being yang lebih rendah bila dibandingkan dengan mahasiswa lainnya. Diener dan Chan (2011) juga menjelaskan bahwa subjective well-being yang rendah berkaitan dengan berbagai permasalahan psikologis.

Subjective well-being merupakan penilaian individu terhadap kehidupannya (Diener, 2000, 2012). Subjective well-being terdiri dari dua dimensi, yaitu dimensi afektif yang terdiri dari afek positif dan afek negatif serta dimensi kognitif yaitu kepuasan hidup (Diener, Oishi, \& Lucas, 2003; Schimmack, 2008). Selain dipengaruhi oleh faktor eksternal, subjective well-being juga dipengaruhi oleh faktor-faktor internal yang ada di dalam diri individu (Compton \& Hoffman, 2013).

Terdapat beberapa faktor yang dapat memengaruhi subjective well-being pada mahasiswa tahun pertama, di antaranya adalah self-efficacy. Self-efficacy merupakan keyakinan individu terhadap kemampuannya menghasilkan tindakan yang diperlukan untuk memperoleh hasil yang diharapkan (Bandura, 1997). Chemers, Hu, dan Garcia (2001) mengemukakan bahwa self-efficacy memiliki pengaruh yang kuat terhadap penyesuaian dan performa akademik mahasiswa tahun pertama. Lebih lanjut, self-efficacy merupakan prediktor kepuasan hidup yang lebih tinggi pada remaja akhir (Vecchio, dkk, 2007). Berbagai penelitian telah membuktikan bahwa terdapat korelasi antara self-efficacy dan subjective well-being (Karademas, Kafetsios, \& Sideridis, 2007; Santos, dkk, 2014). Sehingga self-efficacy menjadi faktor penting yang dapat memprediksi subjective well-being.

Berdasarkan uraian yang telah dikemukakan sebelumnya dapat disimpulkan bahwa self-efficacy dan optimisme berperan penting sebagai faktor-faktor yang dapat memprediksi subjective well-being mahasiswa tahun pertama. Temuan yang diperoleh Chemers, Hu, dan Garcia (2001) menunjukkan bahwa mahasiswa dengan self-efficacy dan optimisme yang lebih tinggi cenderung menganggap periode transisi ke perguruan tinggi sebagai tantangan yang harus ditaklukkan daripada sebuah ancaman yang harus dihindari. Mahasiswa tahun pertama dengan self-efficacy dan optimisme yang tinggi akan memiliki keyakinan pada kompetensi serta pandangan positif dalam menghadapi kehidupan perkuliahan. Kondisi tersebut akan membantu mahasiswa tahun pertama untuk lebih mudah mencapai subjective well-being yang baik di dalam kehidupannya.

Penelitian ini bertujuan untuk mengetahui prediksi self-efficacy dan optimisme terhadap subjective well-being pada mahasiswa tahun pertama. Hasil penelitian ini diharapkan dapat memperkaya khazanah ilmu 
pengetahuan psikologi khususnya di bidang psikologi positif serta dapat menjadi sumber informasi bagi institusi pendidikan khususnya universitas agar dapat memperhatikan subjective well-being mahasiswa tahun pertama serta faktor-faktor yang memengaruhinya. Hipotesis yang diajukan di dalam penelitian ini adalah self-efficacy dan optimisme secara bersama dapat memprediksi subjective well-being pada mahasiswa tahun pertama.

\section{Metode}

\section{Desain penelitian}

Penelitian ini menggunakan pendekatan kuantitatif. Penelitian ini bertujuan untuk mengetahui prediksi self-efficacy dan optimisme terhadap subjective well-being. Teknik analisis data yang digunakan di dalam penelitian ini adalah analisis regresi berganda (multiple regression) yang bertujuan untuk mengetahui kontribusi dua variabel prediktor atau lebih terhadap variabel terikat (Ho, 2014).

\section{Partisipan}

Partisipan di dalam penelitian ini adalah mahasiswa tahun pertama UIN Sultan Syarif Kasim Riau yang berjumlah 372 orang, terdiri dari 121 orang laki-laki dan 251 orang perempuan. Teknik pengambilan sampel yang digunakan adalah dengan menggunakan teknik Proportionate Stratified Random Sampling (Kumar, 2011).

\section{Instrumen penelitian}

Instrumen penelitian yang digunakan pada penelitian ini adalah sebagai berikut:

1. Adaptasi Positive and Negative Affect Schedule (PANAS) yang dikembangkan oleh Watson, Clark, dan Tellegen (1988). Instrumen ini mengukur dimensi afektif subjective well-being. Instrumen ini terdiri dari aitem-aitem mengukur afek positif (skala PA) dan aitem-aitem yang mengukur afek negatif (skala NA). Nilai Cronbach's Alpha instrumen ini adalah 0.771 untuk skala PA, dan 0.833 untuk skala NA.

2. Adaptasi Satisfaction With Life Scale yang dikembangkan oleh Diener, Emmons, Larsen, dan Griffin (1985). Instrumen ini mengukur dimensi kognitif subjective wellbeing. Nilai Cronbach's Alpha instrumen ini adalah 0.797 .

3. Skor subjective well-being diperoleh dari operasi perhitungan sebagai berikut:

$$
z_{\text {score }} S W B=\left(z_{\text {score }} P A-z_{\text {score }} N A\right)+z_{\text {score }} S W L
$$

4. Adaptasi General Self-Efficacy Scale yang dikembangkan oleh Schwarzer dan Jerusalem (1995). Instrumen ini mengukur self-efficacy. Nilai Cronbach's Alpha instrumen ini adalah 0.867 .

5. Adaptasi Life-Orientation Test Revised yang dikembangkan oleh Scheier, Carver, dan Bridges (1994). Instrumen ini mengukur optimisme. Nilai Cronbach's Alpha instrumen ini adalah 0.615.

\section{Teknik analisis data}

Teknik analisis data yang digunakan di dalam penelitian ini adalah analisis regresi berganda (multiple regression). Analisis tersebut dilakukan untuk mengetahui apakah self-efficacy dan optimisme dapat memprediksi subjective well-being. Analisis ini juga dapat memberikan informasi mengenai kontribusi masing-masing prediktor terhadap variabel terikat.

\section{Hasil}

Berikut adalah deskripsi data penelitian ditinjau dari jenis kelamin mahasiswa tahun pertama (lihat Tabel 1): 
Tabel 1

Data Deskripsi Statistik Ditinjau dari Jenis Kelamin

\begin{tabular}{llccc}
\hline Variabel & $\begin{array}{c}\text { Jenis } \\
\text { Kelamin }\end{array}$ & N & Mean & SD \\
\hline Self- & Laki-Laki & 121 & 51.19 & 11.32 \\
Efficacy & Perempuan & 251 & 49.42 & 9.27 \\
Optimisme & Laki-Laki & 121 & 48.83 & 10.47 \\
& Perempuan & 251 & 50.56 & 9.74 \\
Subjective & Laki-Laki & 121 & 48.45 & 9.74 \\
Well- & Perempuan & 251 & 50.74 & 10.06 \\
Being & & & & \\
\hline
\end{tabular}

Sebelum dilakukan uji hipotesis menggunakan analisis regresi berganda, terlebih dahulu dilakukan uji normalitas dan uji linearitas untuk mengetahui apakah data yang diperoleh memenuhi asumsi-asumsi statistik parametrik. Uji normalitas yang dilakukan menunjukkan bahwa data berdistribusi normal, dengan nilai skewness dan kurtosis yang berada dalam rentang -2 hingga 2. Hasil uji linearitas juga menunjukkan hubungan yang linear antara variabel terikat dengan setiap prediktor, dengan nilai $p<0.05$ pada setiap prediktor.

Setelah uji asumsi terpenuhi, maka selanjutnya dilakukan uji hipotesis dengan menggunakan analisis regresi berganda (multiple regression). Hasil analisis menunjukkan bahwa self-efficacy dan optimisme secara bersama dapat memprediksi subjective well-being mahasiswa tahun pertama $(\mathrm{F}(2,369)=53.920 ; p<0.01)$. Nilai Adjusted R Square sebesar 0.222 menunjukkan bahwa self-efficacy dan optimisme dapat menjelaskan subjective well-being sebesar $22.2 \%$, sedangkan sisanya $77.8 \%$ ditentukan oleh variabel lain.

Hasil penelitian juga menunjukkan bahwa nilai $\beta$ pada setiap prediktor positif, artinya terdapat hubungan positif antara masing-masing prediktor terhadap variabel terikat. Selain itu, diketahui pula bahwa selfefficacy memiliki kontribusi yang lebih besar $(\beta=0.403 ; p<0.01)$ bila dibandingkan dengan optimism $(\beta=0.137 ; p<0.01)$. Hasil analisis selengkapnya dapat dilihat pada Tabel 2.

Tabel 2

Nilai $\beta$ Masing-Masing Prediktor

\begin{tabular}{lccc}
\hline \multicolumn{1}{c}{ Variabel } & $\boldsymbol{\beta}$ & $\mathbf{t}$ & $\boldsymbol{p}$ \\
\hline Self-Efficacy & 0.403 & 8.029 & 0.000 \\
Optimisme & 0.137 & 2.735 & 0.007
\end{tabular}

Berdasarkan Tabel 2, maka dapat disusun model persamaan regresi dalam penelitian ini. Persamaan regresi yang diperoleh adalah

$$
\mathrm{Y}=23.002+0.403 \mathrm{X}_{1}+0.137 \mathrm{X}_{2} .
$$

Artinya, jika self-efficacy dan optimisme bernilai 0, maka subjective well-being mahasiswa tahun pertama bernilai 23.002. Jika, self-efficacy dan optimisme masingmasing ditingkatkan senilai 1 satuan, maka subjective well-being mahasiswa tahun pertama akan meningkat sebesar $0.403+0.137$ $=0.540$. Hal ini menunjukkan bahwa kedua prediktor memiliki peran positif dalam memprediksi kenaikan subjective well-being pada mahasiswa tahun pertama.

Selanjutnya, dilakukan uji perbedaan pada setiap variabel ditinjau dari jenis kelamin mahasiswa tahun pertama. Tabel 3 menunjukkan variabel self-efficacy dan optimisme mahasiswa tahun pertama memiliki nilai $F$ hitung masing-masing sebesar 7.636 dan 0.509 dengan nilai $p>0.05$ yang menunjukkan bahwa tidak terdapat perbedaan self-efficacy dan optimisme berdasarkan jenis kelamin. Namun demikian, pada subjective well-being diperoleh nilai $F$ hitung sebesar 0.312 dengan nilai $p<0.05$ yang menunjukkan bahwa terdapat perbedaan subjective well- 
being berdasarkan jenis kelamin.

Tabel 3

Deskripsi Perbedaan Rata-Rata Skor Self-Efficacy, Optimisme, dan Subjective Well-being Mahasiswa Tahun Pertama Ditinjau dari Jenis Kelamin

\begin{tabular}{lllllc}
\hline Variabel & $\begin{array}{c}\text { Jenis } \\
\text { Kelamin }\end{array}$ & N & Mean & F & $\boldsymbol{p}$ \\
\hline Self- & Laki-Laki & 121 & 51.19 & 7.636 & 0.137 \\
Efficacy & Perempuan & 251 & 49.42 & & \\
Optimisme & Laki-Laki & 121 & 48.83 & 0.509 & 0.119 \\
& Perempuan & 251 & 50.56 & & \\
Subjective & Laki-Laki & 121 & 48.45 & 0.312 & 0.039 \\
Well-being & Perempuan & 251 & 50.74 & & \\
& & & & & \\
\hline
\end{tabular}

Sebagaimana hasil analisis regresi berganda yang telah dikemukakan sebelumnya, maka dapat disimpulkan hipotesis dalam penelitian ini diterima. Selfefficacy dan optimisme dapat memprediksi subjective well-being pada mahasiswa tahun pertama. Selain itu, hasil uji perbedaan juga menunjukkan tidak terdapat perbedaan pada self-efficacy dan optimisme ditinjau dari jenis kelamin dan terdapat perbedaan pada subjective well-being ditinjau dari jenis kelamin.

\section{Diskusi}

Hasil penelitian ini menunjukkan bahwa kedua prediktor yaitu self-efficacy dan optimisme secara bersama dapat memprediksi subjective well-being pada mahasiswa tahun pertama. Semakin tinggi self-efficacy dan optimisme, maka semakin tinggi pula subjective well-being mahasiswa tahun pertama. Hasil penelitian ini sejala dengan penelitian Chemers, Hu, dan Garcia (2001) yang menemukan bahwa self-efficacy dan optimisme berperan penting pada kesuksesan dan penyesuaian mahasiswa tahun pertama. Mahasiswa tahun pertama yang memiliki keyakinan pada kompetensi yang dimiliki serta memiliki pandangan yang positif mengenai masa depan akan dapat menghadapi tantangan di dalam kehidupan perkuliahan dengan baik, sehingga lebih sering memunculkan perasaanperasaan yang menyenangkan daripada perasaan-perasaan yang kurang menyenangkan.

Hasil penelitian ini sejalan dengan penelitian Palaniappan dan Swaminathan (2014) yang menemukan bahwa subjective well-being individu secara signifikan meningkat ketika memiliki self-efficacy yang tinggi. Bandura (1997) mengemukakan bahwa self-efficacy memengaruhi tujuan tertentu yang ingin digapai individu, seberapa banyak usaha yang dilakukan, ketekunan dalam menghadapi tantangan dan kegagalan, dan kemampuan untuk mengatasi tuntutan terkait tujuan yang ingin dicapai. Self-efficacy yang dimiliki oleh mahasiswa tahun pertama tergambar dalam bagaimana mahasiswa tahun pertama memiliki keyakinan pada kompetensi yang dimiliki dalam mengatasi berbagai permasalahan dalam berbagai situasi. Keyakinan pada kompetensi yang dimiliki akan menimbulkan perasaan puas pada kehidupan dan memicu emosi-emosi positif pada mahasiswa tahun pertama. Hal ini dikarenakan keyakinan pada kompetensi diri membuat mahasiswa tahun pertama merasa dapat menyelesaikan berbagai permasalahan dan tantangan yang akan dihadapi baik dalam ruang lingkup akademik maupun non-akademik. Temuan Chemers, Hu, dan Garcia (2001) juga menunjukkan bahwa individu dengan self-efficacy yang tinggi akan lebih mampu menghadapi tuntutan pendidikan yang tinggi dan memiliki prestasi akademik yang lebih baik.

Selain itu, Scheier, Carver, dan Bridges (2001) juga menjelaskan bahwa individu yang optimistis cenderung merasakan subjective well-being yang lebih baik bila dibandingkan 
dengan individu yang pesimistis. Optimisme mengarah kepada peningkatan well-being karena dengan pengharapan bahwa masa depan yang akan dihadapi berjalan dengan baik, individu akan meningkatkan engagement dan tetap teguh pada tujuan, sehingga cenderung untuk mencapai tujuan (Dolcos, Moore, \& Katsumi, 2018). Optimisme yang dimiliki oleh mahasiswa tahun pertama tercermin dalam bagaimana mahasiswa tahun pertama memiliki pengharapan yang baik pada hal yang akan dihadapi di masa depan. Hal-hal positif yang diharapkan oleh mahasiswa tahun pertama akan menimbulkan semangat dan memicu perasaan-perasaan positif dan kepuasan dalam menjalankan berbagai aktivitas yang dilakukan oleh mahasiswa tahun pertama. Aspinwall dan Taylor (1992) juga menemukan bahwa mahasiswa tahun pertama yang memiliki optimisme yang tinggi dapat mengatasi stres dan berbagai tekanan saat memasuki perguruan tinggi.

Hasil penelitian ini juga menunjukkan bahwa terdapat perbedaan pada subjective well-being mahasiswa tahun pertama jika ditinjau dari jenis kelamin. Diketahui bahwa mahasiswa perempuan memiliki rerata subjective well-being yang lebih tinggi bila dibandingkan dengan mahasiswa laki-laki. Hasil penelitian ini sejalan dengan temuan Fujita dkk. (1991) yang menemukan bahwa perempuan memiliki tingkat subjective wellbeing yang lebih tinggi dibandingkan laki-laki.

Berdasarkan hasil penelitian ini, terdapat saran praktis bagi institusi pendidikan khususnya universitas. Universitas disarankan untuk memperhatikan subjective well-being mahasiswa tahun pertama dengan baik, karena dalam kondisi subjective well-being yang baik mahasiswa tahun pertama akan dapat menghadapi transisi ke perguruan tinggi secara optimal. Universitas sebaiknya memberikan program-program yang dapat memberikan informasi serta kiat-kiat dalam menghadapi perkuliahan bagi mahasiswa tahun pertama. Sehingga mahasiswa dapat memiliki selfefficacy dan optimisme dalam menghadapi kehidupan perkuliahan yang akan berdampak pada subjective well-being mahasiswa tahun pertama.

\section{Daftar Pustaka}

Aspinwall, L. G., \& Taylor, S. E. (1992). Modeling cognitive adaptation: A longitudinal investigation of the impact of individual differences and coping on college and performance. Journal of Personality and Social Psychology, 63(6), 989-1003. doi: http://dx.doi.org/10.1037/00223514.63.6.989

Bandura, A. (1997). Self-efficacy: The Exercise of Control. New York: Freeman.

Ben-Zur, H. (2003). Happy adolescent: The link between subjective well-being, internal resources, and parental factors. Journal of Youth and Adolescence, 32(2), 67-79. doi: https://dx.doi.org/10.1023/A:102186443 $\underline{2505}$

Carver, C., Scheier, M. F., \& Segerstrom, S. C. (2010). Optimism. Clinical Psychology Review, 30(7), 879-889. doi: https://dx.doi.org/10.1016/j.cpr.2010.01 .006

Chang, E. C., \& Sanna, L. J. (2001). Optimism, pesimism, and positive and negative affectivity in middle-aged adults: A test of cognitive-affective model of 
psychological adjustment. Psychology and Aging, 16(3), 524-531. doi: http://dx.doi.org/10.1037/0882$\underline{7974.16 .3 .524}$

Chemers, M. M., Hu, L., \& Garcia, B. (2001). Academic self-efficacy and first-year college students performance and adjustment. Journal of Educational Psychology, 93(1), 55-64. doi: http://dx.doi.org/10.1037/0022$\underline{0663.93 .1 .55}$

Compton, W. C., \& Hoffman, E. (2013). Positive Psychology: The Science of Happiness and Flourishing $2^{\text {nd }}$ Edition. Belmont, CA: Wadsworth.

Denovan, A., \& Macaskill, A. (2017). Stress and subjective well-being among first year UK undergraduate students. Journal of Happiness Studies, 18(2), 505-525.

doi:

https://dx.doi.org/10.1007/s10902-0169736-y

Diener, E. (2000). Subjective well-being: The science of happiness and a proposal for a national index. American Psychologist, 55(1), 34-43. doi: http://dx.doi.org/10.1037/0003$\underline{066 X .55 .1 .34}$

Diener, E. (2012). New findings and future directions for subjective well-being research. American Psychologist, 67(8), 590-597.

doi: http://dx.doi.org/10.1037/a0029541

Diener, E., \& Chan, M. Y. (2011). Happy people live longer: Subjective wellbeing contributes to health and longetivity. Applied Psychology Health and Well-Being, 3(1), 1-43. doi: http://dx.doi.org/10.1111/j.1758$\underline{0854.2010 .01045 . x}$
Diener, E., Emmons, R., Larsen, R., \& Griffin, S. (1985). The satisfaction with life scale. Journal of Personality Assessment, 49(1), 71-75. doi: https://dx.doi.org/10.1207/s15327752jp a4901_13

Diener, E., Oishi, S., \& Lucas, R. E. (2003). Personality, culture, and subjective wellbeing: Emotional and cognitive evaluations of life. Annual Review of Psychology, 54(1), 403-425. doi: https://dx.doi.org/10.1146/annurev.psyc $\underline{\text { h.54.101601.145056 }}$

Dolcos, S., Moore, M., \& Katsumi, Y. (2018). Neuroscience and well-being. Dalam E. Diener, S. Oishi, \& L. Tay (Eds.), Handbook of Well-being. Salt Lake City, UT: DEF Publishers.

Fujita, F., Diener, E., \& Sandvik, E. (1991). Gender differences in negative affect and well-being. Journal of Personality and Social Psychology, 61(3), 427-434. doi: http://dx.doi.org/10.1037/0022$\underline{3514.61 .3 .427}$

Gall, T. L., Evans, D. R., \& Bellerose, S. (2000). Transition to first-year university: patterns of change in adjustment across life domains and time. Journal of Social and Clinical Psychology, 19(4), 544-567. doi: https://dx.doi.org/10.1521/jscp.2000.19. 4.544

Ho, R. (2014). Handbook of Univariate and Multivariate Data Analysis with IBM SPSS $2^{\text {nd }}$ Edition. FL: CRC Press, Taylor $\&$ Francis Group.

Hou, L., \& Liu, Y. (2016). The influence of stressful life events of college students on subjective well-being: The mediation effect of the operational effectiveness. 
Open Journal of Social Sciences, 4(6), 70-76. doi: https://dx.doi.org/10.4236/jss.2016.460 $\underline{08}$

Karademas, E. C., Kafetsios, K., \& Sideridis, G. D. (2007). Optimism, self-efficacy and information processing of threat and well-being related stimuli. Stress and Health, 23(5), 285-294. doi: http://dx.doi.org/10.1002/smi.1147

Kulaksizoğlu, A., \& Topuz, C. (2014). Subjective well-being levels of university students. Journal of Educational and Instructional Studies in the World, 4(3), 25-34. Diambil dari https://www.ncbi.nlm.nih.gov/pmc/artic les/PMC4449511/

Kumar, R. (2011). Research Methodology: A Step-by-step Guide for Beginners $3^{\text {rd }}$ Edition. London: Sage Publication.

Lucas, R. E., Diener, E., \& Suh, E. M. (1996). Discriminant validity of well-being measures. Journal of Personality and Social Psychology, 71(3), 616-628. doi: http://dx.doi.org/10.1037/0022$\underline{3514.71 .3 .616}$

Margolis, S., \& Lyubomirsky, S. (2018). Cognitive outlooks and well-being. Dalam E. Diener, S. Oishi, \& L. Tay (Eds.), Handbook of Well-Being. Salt Lake City, UT: DEF Publishers.

Montgomery, M. J., \& Côté, J. E. (2003). College as a transition to adulthood. Dalam G. R. Adams, \& M. D. Berzonsky (Eds.), Blackwell Handbook of Adolescence. Malden: Blackwell Publishing Ltd.

Palaniappan, D., \& Swaminathan, V. D. (2014). Influence of Self-Efficacy,
Perceived Parental Autonomy Support, Perceived Social Support on Subjective Well-Being of Adolescents through Flow Experiences. International Journal of Education and Psychological Research, 3(1), 32-36. Diambil dari http://ijepr.org/doc/V3_Is1_March14/ij7 .pdf

Pavot, W. (2018). The cornerstone of research on subjective well-being: Valid assessment methodology. Dalam E. Diener, S. Oishi, \& L. Tay (Eds.), Handbook of well-being. Salt Lake City, UT: DEF Publishers.

Santos, M. C. J., Magramo Jr., C. S. M., Oguan Jr., F., \& Paat, J. J. (2014). Establishing the relationship between general selfefficacy and subjective well-being among college students. Asian Journal of Management Sciences \& Education, 3(1), 1-12. Diambil dari http://www.ajmse.leenaluna.co.jp/AJMSEPDFs/Vol.3(1)/AJMS E2014(3.1-01).pdf

Scheier, M. F., \& Carver, C. S. (1985). Optimism, coping, and health: Assessment and implications of generalized outcome expectancies. Health Psychology, 4(3), 219-247. doi: http://dx.doi.org/10.1037/02786133.4.3.219

Scheier, M. F., \& Carver, C. S. (1987). Dispositional optimism and physical well-being: The influence of generalized outcome expectancies on health. Journal of Personality, 55(2), 169-210. doi: https://dx.doi.org/10.1111/j.14676494.1987.tb00434.x

Scheier, M. F., \& Carver, C. S. (1993). On the power of positive thinking: The benefits 
of being optimistic. Current Directions in Psychological Science, 2(1), 26-30. doi: $\quad$ https://dx.doi.org/10.1111/14678721.ep10770572

Scheier, M. F., Carver, C. S., \& Bridges, M. W. (1994). Distinguishing optimism from neuroticism (and trait anxiety, selfmastery, and self-esteem): A reevaluation of the life orientation test. Journal of Personality and Social Psychology, 67(6), 1063-1078. doi: http://dx.doi.org/10.1037/0022$\underline{3514.67 .6 .1063}$

Scheier, M. F., Carver, C. S., \& Bridges, M. W. (2001). Optimism, pessimism, and psychological well-being. Dalam E. C. Chang (Ed.), Optimism and Pessimism: Implications for Theory, Research, and Practice. Washington, DC: American Psychological Association.

Schimmack, U. (2008). The structure of subjective well-being. Dalam M. Eid, \& R. J. Larsen (Eds.), The Science of Subjective Well-being. New York: Guilford Press.

Schwarzer, R., \& Jerusalem, M. (1995). Generalized self-efficacy scale. Dalam M. Johnston, S. Wright, \& J. Weinman (Eds.), Measures in Health Psychology: A User's Portfolio, Causal and Control Beliefs. Windsor: NFER-NELSON.

Vecchio, G. M., Gerbino, M., Pastorelli, C., Del Bove, G., \& Caprara, G. V. (2007). Multi-faceted self-efficacy beliefs as predictors of life satisfaction in late adolescence. Personality and Individual Differences, 43(7), 1807-1818. doi: https://dx.doi.org/10.1016/j.paid.2007.0 $\underline{5.018}$

Watson, D., Clark, L. A., \& Tellegen, A.
(1988). Development and validation of brief measures of positive and negative affect the PANAS scales. Journal of Personality and Social Psychology, 54(6), 1063-1070. doi: https://dx.doi.org/10.1016/j.paid.2007.0 $\underline{5.018}$ 